\title{
A Novel Hexatungstate Fragment Stabilized by Dimethyltin Groups: $\left[\left\{\left(\mathrm{CH}_{3}\right)_{2} \mathrm{Sn}\right\}_{2}\left(\mathrm{~W}_{6} \mathrm{O}_{22}\right)\right]^{4-}$
}

Santiago Reinoso, Michael H. Dickman and Ulrich Kortz*

School of Engineering and Science, International University Bremen, P.O. Box 750 561, 28725 Bremen, Germany

E-mail: u.kortz@iu-bremen.de, Fax:+49-421-200 3229

\section{Supporting Information}

Figure S1. FTIR spectrum of $\left[\mathrm{C}\left(\mathrm{NH}_{2}\right)_{3}\right]_{4}\left[\left\{\left(\mathrm{CH}_{3}\right)_{2} \mathrm{Sn}\right\}_{2}\left(\mathrm{~W}_{6} \mathrm{O}_{22}\right)\right] \cdot 2 \mathrm{H}_{2} \mathrm{O}(\mathbf{1 a})$.

Figure S2. TGA and DSC curves of 1a. 


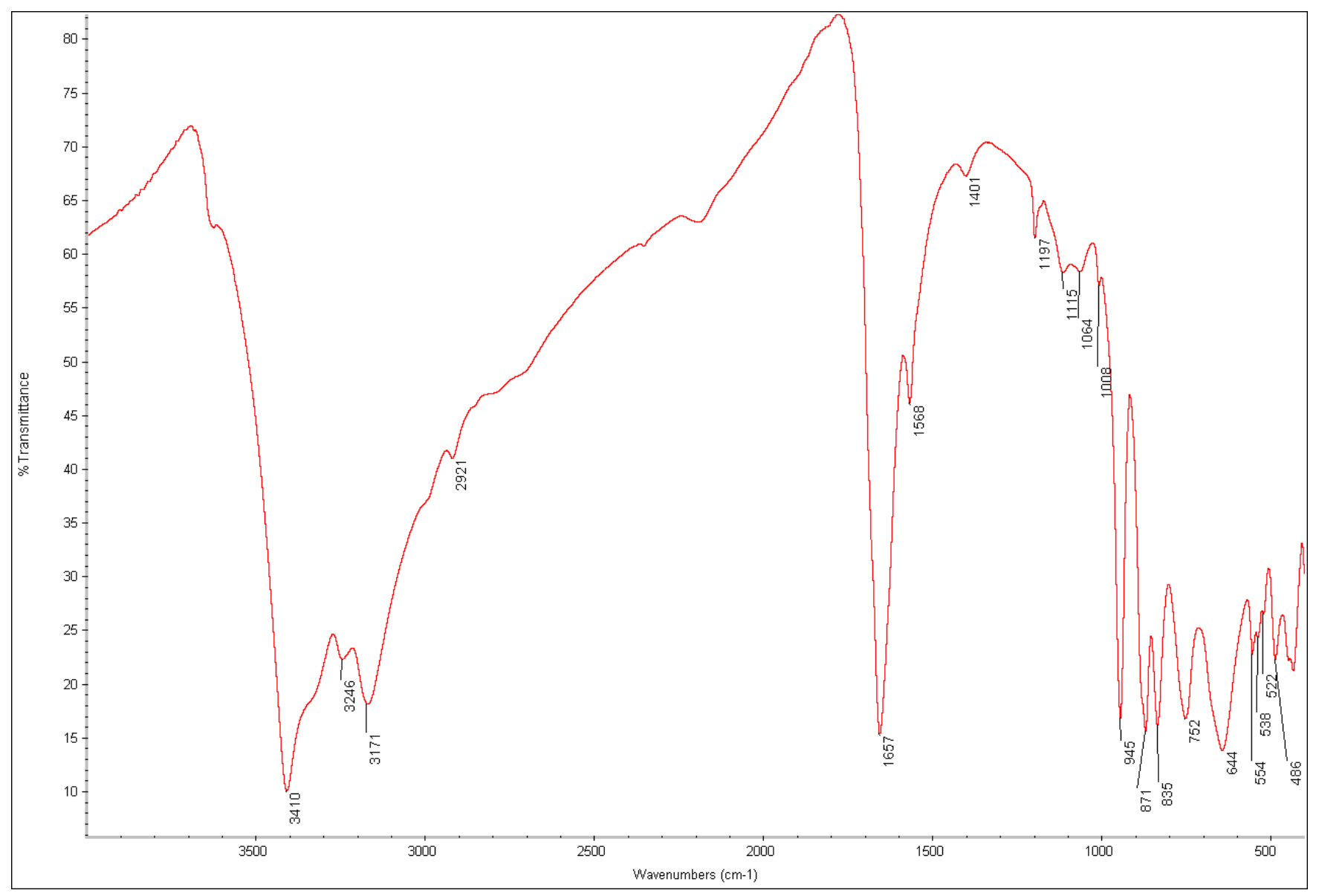

Figure S1 


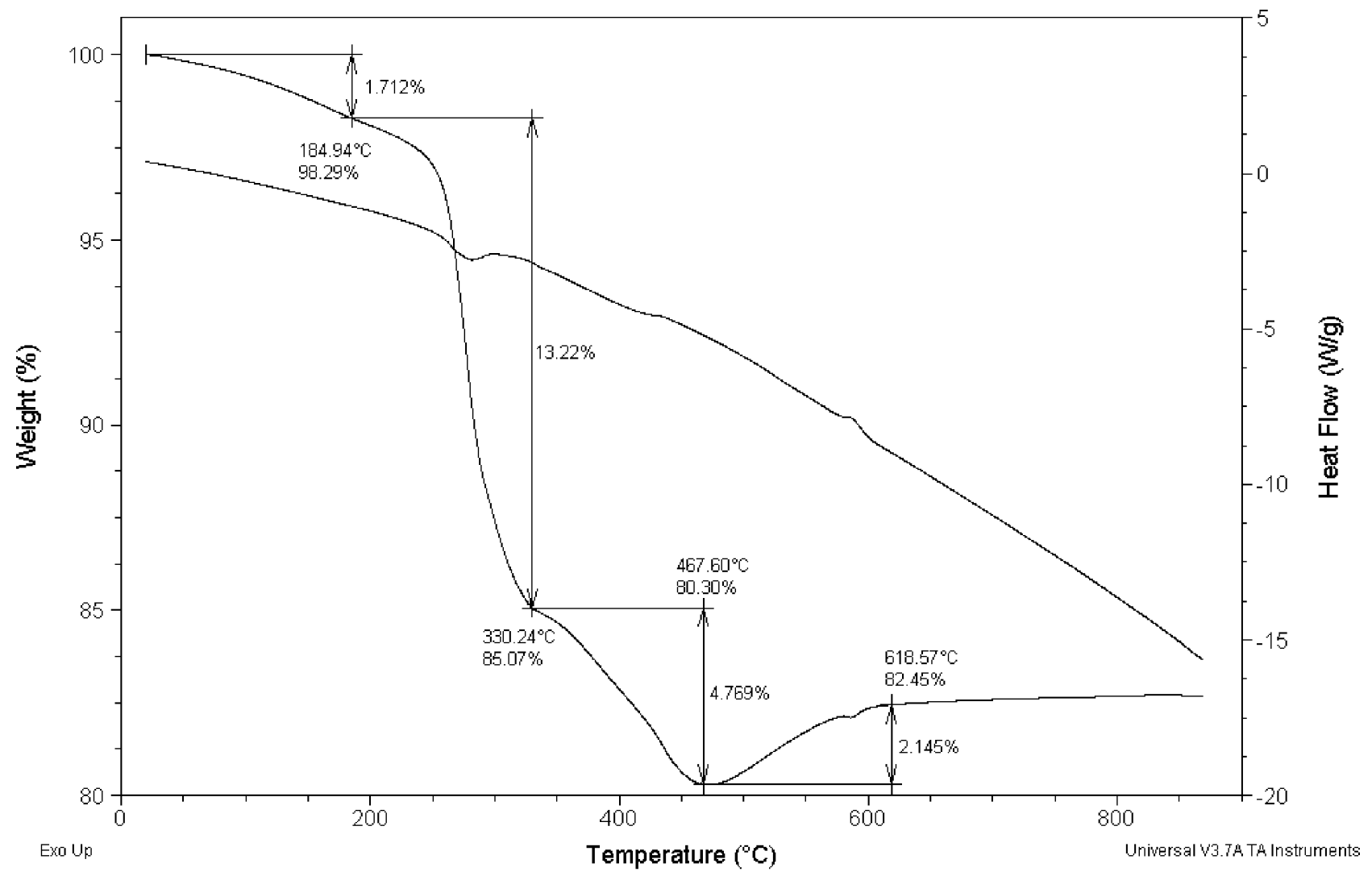

Figure S2 